\title{
Successful treatment of repeated hematemesis secondary to post- sclerotherapy esophageal ulcer in a cirrhotic patient: A case report
}

\author{
Zhaohui Bai ${ }^{1,2,}$, Xiaozhong Guo ${ }^{1, \S}$, Xiaodong Shao ${ }^{1}$, Yingying $\mathrm{Li}^{1,3}$, Qianqian $\mathrm{Li}^{1,4}$, Xiangbo Xu ${ }^{1,2}$, \\ Zhendong Liang, Jiao Deng ${ }^{5}$, Xia Zhang ${ }^{6}$, Hongyu Li ${ }^{1, *}$, Xingshun $\mathbf{Q i}^{1, *}$ \\ ${ }^{1}$ Department of Gastroenterology, General Hospital of Shenyang Military Area, Shenyang, Liaoning, China; \\ ${ }^{2}$ Postgraduate College, Shenyang Pharmaceutical University, Shenyang, Liaoning, China; \\ ${ }^{3}$ Postgraduate College, Jinzhou Medical University, Jinzhou, Liaoning, China; \\ ${ }^{4}$ Postgraduate College, Dalian Medical University, Dalian, Liaoning, China; \\ ${ }^{5}$ Department of Pharmacology, General Hospital of Shenyang Military Area, Shenyang, Liaoning, China; \\ ${ }^{6}$ No. 4 People Hospital of Shenyang City, Shenyang, Liaoning, China.
}

\begin{abstract}
Summary Esophageal variceal bleeding is a common lethal complication of cirrhosis. Endoscopic injection sclerotherapy (EIS) is one of the major endoscopic approaches for treating esophageal variceal bleeding. However, complications may occur after EIS, which mainly include retrosternal discomfort/pain, dysphagia, re-bleeding, esophageal ulcer, esophageal strictures, and esophageal perforation, etc. In this article, we reported a 36-year-old male who developed esophageal ulcer related bleeding after EIS. Currently, there is no consensus on the treatment strategy for esophageal ulcer-related bleeding after EIS. In the present case, the following treatment strategy may be effective for ulcer related bleeding. The first step is to inhibit gastric acid secretion and reduce portal pressure by intravenous infusion of esomeprazole and somatostatin, respectively. The second is local hemostasis by oral norepinephrine and lyophilizing thrombin powder. The third is to protect digestive tract mucosa by oral Kangfuxin Ye and aluminum phosphate.
\end{abstract}

Keywords: Esophageal varices, endoscopic injection sclerotherapy, endoscopic band ligation, esophageal ulcer, portal hypertension

\section{Introduction}

Esophageal and gastric varices are common complications of chronic liver diseases. On the other hand, esophageal varices are one of the most common causes of acute upper gastrointestinal bleeding $(1,2)$. The 6-week mortality rate of each variceal bleeding episode is $15-20 \%$, ranging from $0 \%$ among patients with Child class A to approximately 30\% among patients with Child class C (3-5). Before the 1970s, the major treatment options of variceal bleeding included vasoconstrictors and surgical intervention. Since the

\footnotetext{
${ }^{\S}$ These authors contributed equally to this work.

*Address correspondence to:

Drs. Xingshun Qi and Hongyu Li, Department of Gastroenterology, General Hospital of Shenyang Military Area, No. 83 Wenhua Road, Shenyang 110840, Liaoning Province, China.

E-mail: xingshunqi@126.com (Qi X); 13309887041@163. com $(\mathrm{Li} \mathrm{H})$
}

mid-1970s, endoscopic injection sclerotherapy (EIS) has been gradually employed for the treatment of esophageal variceal bleeding (6). EIS is superior to vasoconstrictors or balloon tamponade in controlling acute esophageal variceal bleeding $(7,8)$. However, EIS is associated with a number of complications, such as esophageal ulcer, stenosis, and perforation (9). Among them, the incidence of ulcer related bleeding after EIS is 4.3-12.8\% (1019). At present, there is no consensus on the treatment strategy for esophageal ulcer-related bleeding after EIS. In this article, we reported a case of esophageal ulcer related bleeding after EIS and discussed the management of this complication.

\section{Case presentation}

On June 17, 2018, a 36-year-old male with a 19-month history of hepatitis $\mathrm{C}$ virus related liver cirrhosis was admitted to the Department of Emergency of our hospital due to intermittent hematemesis for 11 hours. 


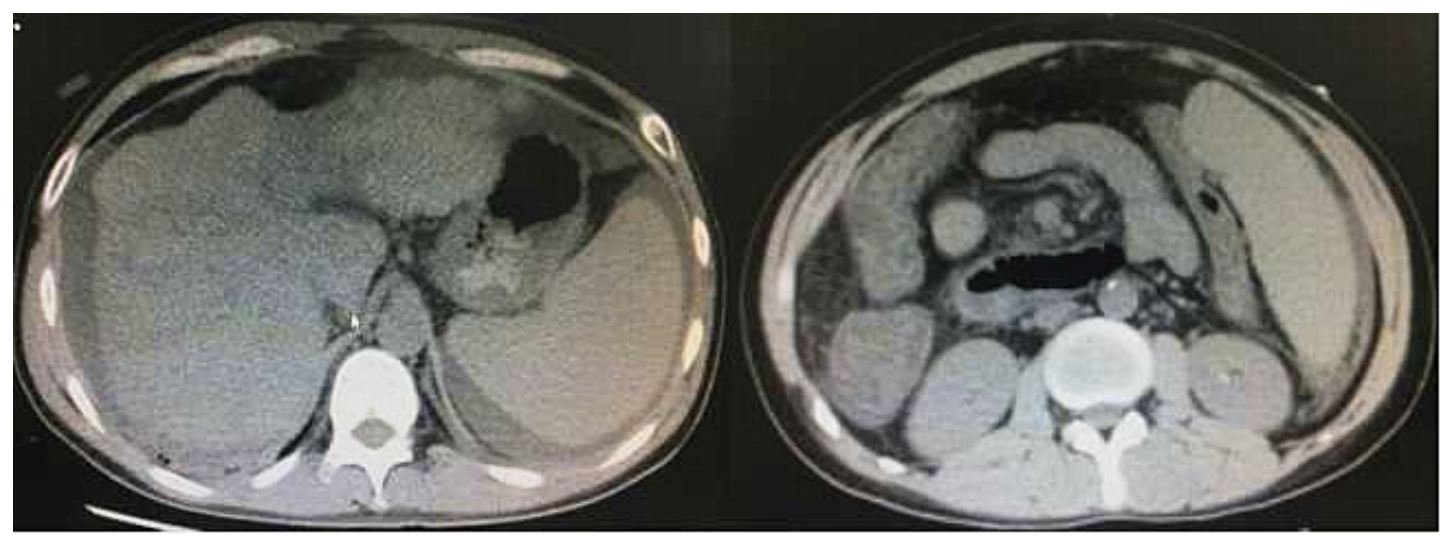

Figure 1. Abdominal CT scans showed cirrhosis, splenomegaly, ascites, and left renal calculus.

The volume of fresh blood vomited was about $300 \mathrm{~mL}$. Immediately, infusion of terlipressin $2 \mathrm{mg}$, esomeprazole $80 \mathrm{mg}$, somatostatin $6 \mathrm{mg}$, hemocoagulase injection 2 $\mathrm{u}$, and hydroxyethyl starch sodium chloride injection $500 \mathrm{~mL}$ was given at the Department of Emergency. He developed hematemesis again. The volume of fresh blood vomited was about $300 \mathrm{ml}$. On June 18, 2018, he was transferred to our department. He had undergone endoscopic band ligation (EBL) with and without gastric variceal tissue adhesive injection for the treatment of acute variceal bleeding three times (on March 1, 2017, August 1, 2017, and March 27, 2018). He had a 10-year history of smoking and drinking.

After his admission, the patient did not have hematemesis or melena. Heart rate was 78 b.p.m. and blood pressure was $132 / 80 \mathrm{mmHg}$. Physical examinations demonstrated that his skin and sclera were yellow. On laboratory tests, red blood cell $(\mathrm{RBC})$ was $4.05 \times 10^{12} /$ $\mathrm{L}$ (reference range: 4.0-5.5 $\times 10^{12} / \mathrm{L}$ ), hemoglobin $(\mathrm{Hb})$ was $125 \mathrm{~g} / \mathrm{L}$ (reference range: $110-150 \mathrm{~g} / \mathrm{L}$ ), hematocrit (HCT) was $38.2 \%$ (reference range: $35-45 \%$ ), white blood cell $\left(\mathrm{WBC}\right.$ ) was $2.9 \times 10^{9} / \mathrm{L}$ (reference range: 3.5 $\left.9.5 \times 10^{12} / \mathrm{L}\right)$, percentage of granulocyte $(\mathrm{GR} \%)$ was $63.0 \%$ (reference range: $45-75 \%$ ), total bilirubin (TBIL) was $62.2 \mu \mathrm{mol} / \mathrm{L}$ (reference range: 5.1-22.2 $\mu \mathrm{mol} / \mathrm{L}$ ), direct bilirubin (DBIL) was $18.7 \mu \mathrm{mol} / \mathrm{L}$ (reference range: $0-8.6 \mu \mathrm{mol} / \mathrm{L}$ ), alanine amino-transaminase (ALT) was $30.43 \mathrm{U} / \mathrm{L}$ (reference range: 9-50 U/L), aspartate amino-transaminase (AST) was $61.38 \mathrm{U} / \mathrm{L}$ (reference range: $15-40 \mathrm{U} / \mathrm{L}$ ), alkaline phosphatase (AKP) was 146.97 U/L (reference range: 45-125 U/L), $\gamma$-glutamyl transpeptidase (GGT) was $33.90 \mathrm{U} / \mathrm{L}$ (reference range: 10-60 U/L), prothrombin time (PT) was 21.5 seconds (reference range: 11.5-14.5 seconds), and international normalized ratio (INR) was 1.87. Abdominal computed tomography (CT) scans showed cirrhosis, splenomegaly, ascites, and left renal calculus (Figure 1). His ChildPugh score was 12 points. Infusion of terlipressin $2 \mathrm{mg}$ per 12 hours, esomeprazole $80 \mathrm{mg}$ per 10 hours, polyene phosphatidylcholine $465 \mathrm{mg}$ per day, isoglycyrrhizinate $150 \mathrm{mg}$ per day, ademetionine 1,000 mg per day, and levofloxacin $0.5 \mathrm{~g}$ per day was given.
On June 19, 2018, the patient did not have hematemesis or melena. Laboratory tests demonstrated that $\mathrm{WBC}$ was $3.2 \times 10^{9} / \mathrm{L}$, GR\% was $63.0 \%$, RBC was $3.85 \times 10^{12} / \mathrm{L}$, Hb was $125 \mathrm{~g} / \mathrm{L}$, HCT was $36 \%$, TBIL was $78.8 \mu \mathrm{mol} / \mathrm{L}$, DBIL was $36.2 \mu \mathrm{mol} / \mathrm{L}$, ALT was $29.03 \mathrm{U} / \mathrm{L}, \mathrm{AST}$ was $53.49 \mathrm{U} / \mathrm{L}$, AKP was $115.6 \mathrm{U} /$ $\mathrm{L}$, GGT was $31.46 \mathrm{U} / \mathrm{L}$, albumin (ALB) was $31.3 \mathrm{~g} /$ L (reference range: 40-55 g/L), PT was 23.1 seconds, and INR was 2.04. Endoscopy showed three visible thrombi on the surface of the esophageal varices (Figure 2). Sclerotherapy with lauromacrogol $5 \mathrm{~mL}$ followed by tissue adhesive $0.5 \mathrm{~mL}$ was successfully performed by our endoscopist (Figure 2). After endoscopic treatment, terlipressin and esomeprazole were discontinued. Oral propranolol $10 \mathrm{mg}$ per 12 hours was given.

On June 21, 2018, the patient developed hematemesis after sneezing. The volume of fresh blood vomited was about $100 \mathrm{ml}$. Laboratory tests demonstrated that WBC was $4.8 \times 10^{9} / \mathrm{L}$, GR\% was $66.9 \%$, RBC was $3.81 \times$ $10^{12} / \mathrm{L}$, Hb was $117 \mathrm{~g} / \mathrm{L}$, HCT was $35.8 \%$, TBIL was $53.9 \mu \mathrm{mol} / \mathrm{L}$, DBIL was $34.5 \mu \mathrm{mol} / \mathrm{L}$, ALT was 25.55 $\mathrm{U} / \mathrm{L}$, AST was $37.92 \mathrm{U} / \mathrm{L}$, AKP was $124.34 \mathrm{U} / \mathrm{L}$, GGT was $33.1 \mathrm{U} / \mathrm{L}$, and ALB was $29.8 \mathrm{~g} / \mathrm{L}$. Infusion of somatostatin 3,000 u per 12 hours and esomeprazole 80 mg per 10 hours was given.

On June 22, 2018, endoscopy showed two ulcer lesions (Figure 3). At 15:00 o'clock, the patient developed hematemesis again. The volume of fresh blood vomited was about $100 \mathrm{~mL}$. Laboratory tests demonstrated that WBC was $4.8 \times 10^{9} / \mathrm{L}$, GR\% was $76.1 \%$, RBC was $3.65 \times 10^{12} / \mathrm{L}$, Hb was $114 \mathrm{~g} / \mathrm{L}$, and $\mathrm{HCT}$ was $34.6 \%$. Intravenous infusion of esomeprazole $80 \mathrm{mg}$ per 10 hours was continued. The dosage of somatostatin was changed to 3,000 u per 6 hours. In addition, intravenous infusion of carbazochrome sodium sulfonate $80 \mathrm{mg}$ per day and oral lyophilizing thrombin powder 5,000 $\mathrm{u}$ per day, norepinephrine $4 \mathrm{mg}$ per day, and aluminum phosphate $20 \mathrm{~g}$ three times a day were given.

On June 24, 2018, the patient developed hematemesis again. The volume of fresh blood vomited was about 10 $\mathrm{mL}$. Oral lyophilizing thrombin powder $5,000 \mathrm{u}$ per day and norepinephrine $2 \mathrm{mg}$ per day were given again. 


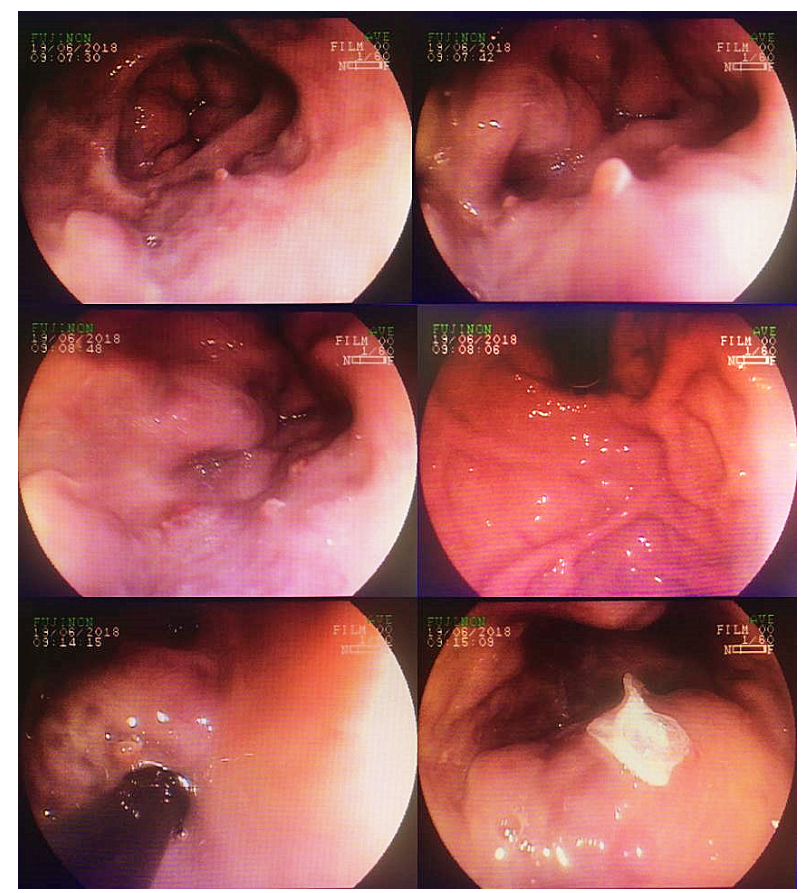

Figure 2. Endoscopy on June 19, 2018 showed three visible thrombi on the surface of esophageal varices, and then EIS was performed.

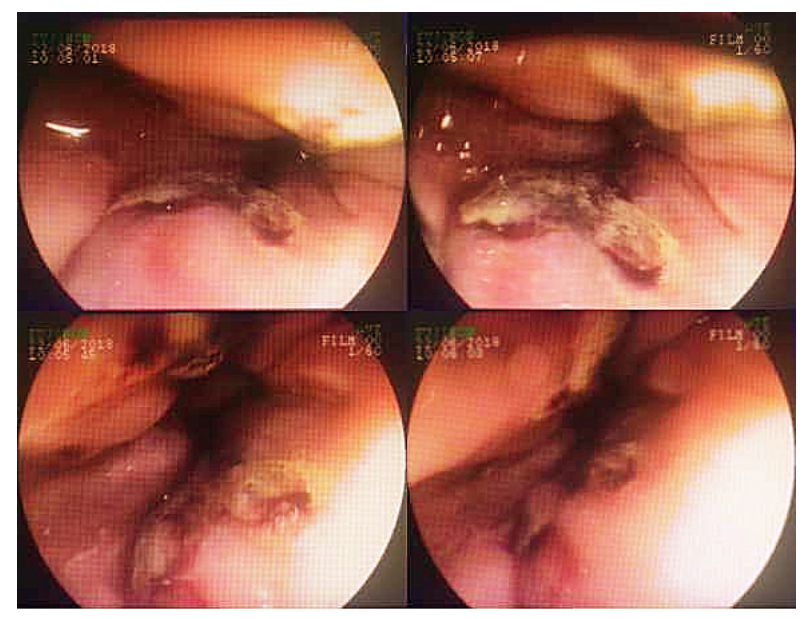

Figure 3. Endoscopy on June 22, 2018 showed two ulcer lesions.

On June 26, 2018, the patient did not have hematemesis or melena. Laboratory tests demonstrated that $\mathrm{WBC}$ was $4.1 \times 10^{9} / \mathrm{L}$, GR\% was $71 \%$, RBC was 3.63 $\times 10^{12} / \mathrm{L}$, Hb was $116 \mathrm{~g} / \mathrm{L}$, HCT was $35.4 \%$, TBIL was $45.5 \mu \mathrm{mol} / \mathrm{L}$, DBIL was $28.0 \mu \mathrm{mol} / \mathrm{L}$, ALT was 13.95 $\mathrm{U} / \mathrm{L}$, AST was $22.92 \mathrm{U} / \mathrm{L}$, AKP was $108 \mathrm{U} / \mathrm{L}$, GGT was $28.57 \mathrm{U} / \mathrm{L}, \mathrm{ALB}$ was $27.0 \mathrm{~g} / \mathrm{L}$, PT was 23.4 seconds, and INR was 2.07. Isoglycyrrhizinate was discontinued. The dosage of somatostatin was changed to 3,000 u per 12 hours. Albumin $10 \mathrm{~g}$ per day was given. Oral Kangfuxin Ye, which is a traditional Chinese medicine drug for treatment of the damage of digestive tract mucosa, 10 $\mathrm{mL}$ per day was given.

On June 27, 2018, the patient developed hematemesis again. The volume of fresh blood vomited was about 30 $\mathrm{mL}$. Intravenous infusion of somatostatin was changed to
3,000 u per 6 hours. Oral lyophilizing thrombin powder $5,000 \mathrm{u}$ per day and norepinephrine $4 \mathrm{mg}$ per day were given again.

After that, he did not have hematemesis or melena. On June 30, 2018, laboratory tests demonstrated that WBC was $4.1 \times 10^{9} / \mathrm{L}$, GR\% was $71 \%$, RBC was 3.63 $\times 10^{12} / \mathrm{L}$, Hb was $116 \mathrm{~g} / \mathrm{L}$, HCT was $35.4 \%$, TBIL was $45.5 \mu \mathrm{mol} / \mathrm{L}$, DBIL was $28.0 \mu \mathrm{mol} / \mathrm{L}$, ALT was 13.95 $\mathrm{U} / \mathrm{L}$, AST was $22.92 \mathrm{U} / \mathrm{L}$, AKP was $108 \mathrm{U} / \mathrm{L}$, GGT was $28.57 \mathrm{U} / \mathrm{L}$, ALB was $27.0 \mathrm{~g} / \mathrm{L}$, PT was 23.4 seconds, and INR was 2.07. The dosage of aluminum phosphate was changed to $20 \mathrm{~g}$ per day.

On July 1, 2018, the patient did not have hematemesis or melena. Somatostatin, levofloxacin, and carbazochrome sodium sulfonate were discontinued.

On July 4, 2018, the patient did not have hematemesis and then was discharged. Laboratory tests demonstrated that $\mathrm{WBC}$ was $3.2 \times 10^{9} / \mathrm{L}$, GR\% was $77 \%$, RBC was $3.37 \times 10^{12} / \mathrm{L}$, Hb was $111 \mathrm{~g} / \mathrm{L}$, HCT was $32.5 \%$, TBIL was $31.7 \mu \mathrm{mol} / \mathrm{L}$, DBIL was $21.4 \mu \mathrm{mol} / \mathrm{L}$, ALT was 8.20 $\mathrm{U} / \mathrm{L}$, AST was $22.94 \mathrm{U} / \mathrm{L}$, AKP was $103 \mathrm{U} / \mathrm{L}$, GGT was $28.89 \mathrm{U} / \mathrm{L}$, and ALB was $31.7 \mathrm{~g} / \mathrm{L}$. We recommended the patient to take medication at home, including oral Kangfuxin Ye $10 \mathrm{~mL}$ per day, aluminum phosphate 20 g per day, propranolol $10 \mathrm{mg}$ twice a day, and polyene phosphatidylcholine $456 \mathrm{mg}$ three times a day.

On August 6, 2018, the patient underwent follow-up endoscopic surveillance. Laboratory tests demonstrated that $\mathrm{WBC}$ was $2.2 \times 10^{9} / \mathrm{L}$, GR\% was $54 \%$, RBC was 4.05 $\times 10^{12} / \mathrm{L}$, Hb was $129 \mathrm{~g} / \mathrm{L}$, HCT was $38.8 \%$, TBIL was $39.9 \mu \mathrm{mol} / \mathrm{L}$, DBIL was $23.3 \mu \mathrm{mol} / \mathrm{L}$, ALT was $34.72 \mathrm{U} /$ L, AST was 50.36 U/L, AKP was $159.70 \mathrm{U} / \mathrm{L}$, GGT was $28.48 \mathrm{U} / \mathrm{L}$, ALB was $36.1 \mathrm{~g} / \mathrm{L}$, PT was 19.5 seconds, and INR was 1.64.

On August 7, 2018, a follow-up endoscopy showed several esophageal varices with red color sign, and then EBL was performed. Mild varices were found in the gastric fundus (Figure 4).

On August 11, 2018, the patient did not have hematemesis or melena. Laboratory tests demonstrated that $\mathrm{WBC}$ was $2.5 \times 10^{9} / \mathrm{L}$, GR\% was $56.2 \%$, RBC was $3.67 \times 10^{12} / \mathrm{L}$, Hb was $117 \mathrm{~g} / \mathrm{L}$, HCT was $35 \%$, TBIL was $38.4 \mu \mathrm{mol} / \mathrm{L}$, DBIL was $21 \mu \mathrm{mol} / \mathrm{L}$, ALT was 22.39 $\mathrm{U} / \mathrm{L}$, AST was $32 \mathrm{U} / \mathrm{L}$, AKP was $170.49 \mathrm{U} / \mathrm{L}$, GGT was $29.64 \mathrm{U} / \mathrm{L}, \mathrm{ALB}$ was $32.1 \mathrm{~g} / \mathrm{L}$, PT was 20.6 seconds, and INR was 1.56. The patient was discharged. At the time of writing this manuscript, he is well without any other complaints.

\section{Discussion}

Currently, the first-line treatment option of acute variceal bleeding should be endoscopic treatment combined with vasoconstrictors (20). However, according to the current practice guideline, covered transjugular intrahepatic portosystemic shunt (TIPS) should be considered as the treatment of choice in the cases when endoscopic 


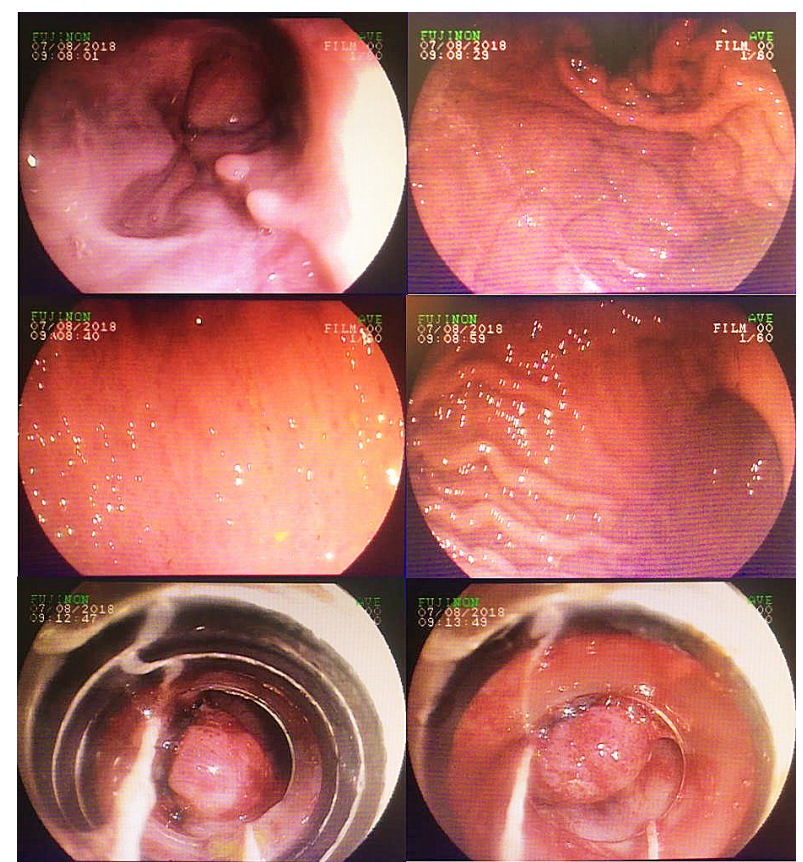

Figure 4. Endoscopy on August 7, 2018 showed mild varices on esophagus and gastric fundus with red color sign, and then EBL was performed.

treatment fails (21). Our case underwent endoscopic treatment for variceal bleeding many times. We recommended the use of TIPS, but he and his relatives refused.

EBL should be preferred, when endoscopic treatment is considered for the management of acute variceal bleeding in cirrhotic patients $(20,21)$. Among the patients with acute esophageal variceal bleeding, the rate of rebleeding in patients treated with EBL was lower than in those treated with EIS. The reason may be that EIS led to a sustained rise in hepatic venous pressure gradient, followed by an increased re-bleeding rate (22). A metaanalysis demonstrated that EBL was superior to EIS in terms of re-bleeding, complications, and variceal eradication (23). However, in our case, three visible thrombi were densely arranged on the surface of varices. Our endoscopist suggested that the ligation ring would pass over the thrombi and then lead to active bleeding during the procedure, if EBL was continued. Indeed, the American Society for Gastrointestinal Endoscopy (ASGE) guideline recommends that EIS may be performed in the case that EBL is technically difficult (24). After a comprehensive consideration, EIS was finally performed.

Adverse events of EIS include fever, retrosternal discomfort/pain, dysphagia, injection-induced bleeding, esophageal ulcers, esophageal strictures, esophageal perforation, pleural effusion, acute respiratory distress syndrome, and infection $(9,25)$. Our case developed esophageal ulcer related bleeding after EIS (Figure 3). We reviewed the literature regarding the occurrence of re-bleeding secondary to esophageal ulcer after EBL or EIS (Table 1). As for most of esophageal ulcers

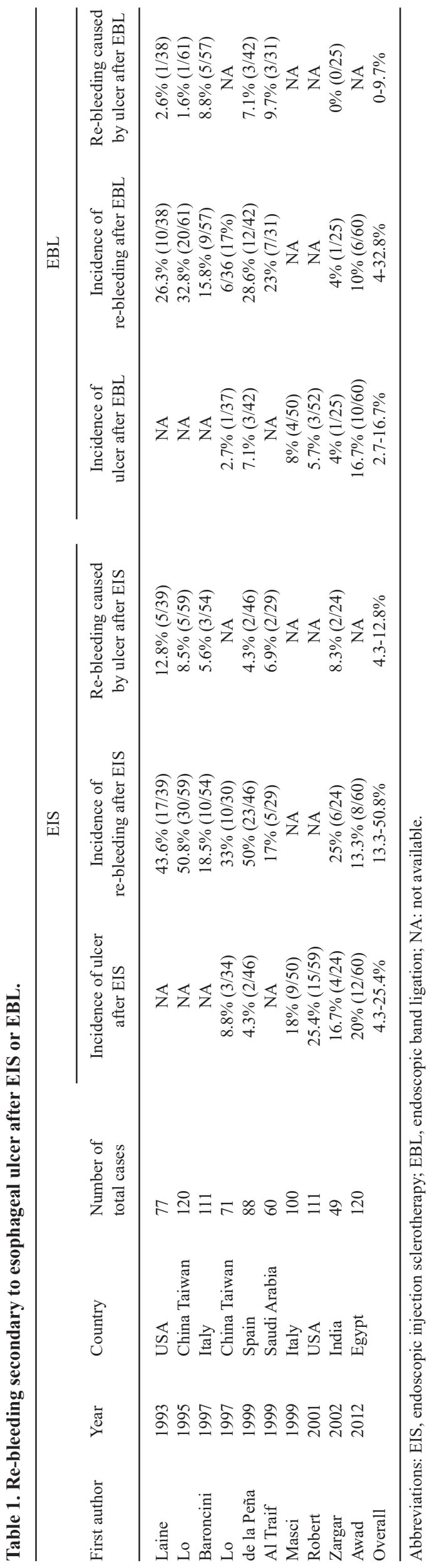




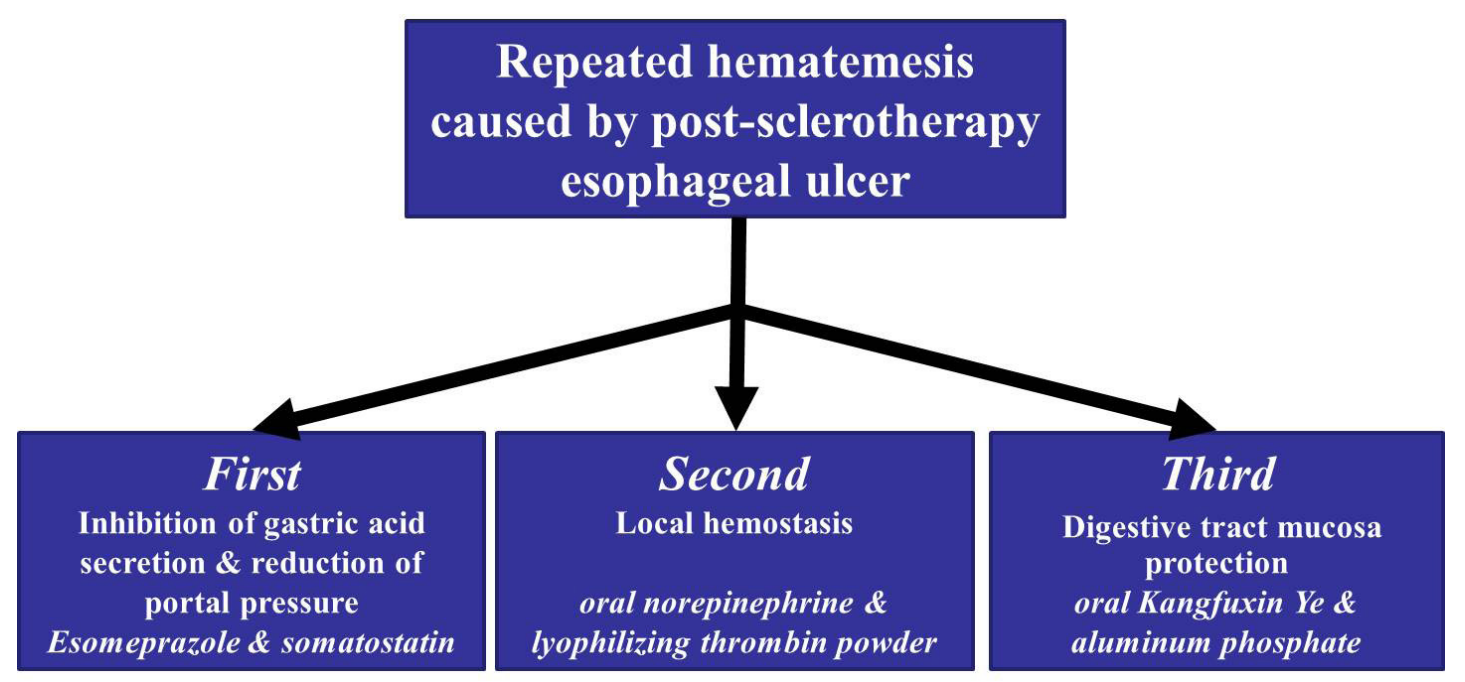

Figure 5. Treatment procedure in this patient.

without bleeding after EIS, no special treatment was required (15). The prophylactic use of acid suppression drugs after endoscopic treatment for gastroesophageal varices remains uncertain (26). By comparison, as for active bleeding secondary to esophageal ulcers, endoscopic injection of epinephrine might be useful for hemostasis (15). Our case had active ulcers bleeding after EIS. Our treatment strategy was as follows: the first was to inhibit gastric acid secretion and reduce portal pressure by intravenous infusion of esomeprazole and somatostatin, respectively; the second was local hemostasis by oral norepinephrine and lyophilizing thrombin powder; the third was to protect digestive tract mucosa by oral Kangfuxin Ye and aluminum phosphate (Figure 5). Despite his ulcer related bleeding stopped, the duration of treatment was long.

In conclusion, esophageal ulcer is a major cause of early re-bleeding after EIS. However, at present, there is no consensus regarding treatment strategy of esophageal ulcer related bleeding after EIS. Our successful treatment strategy may be validated in a large-scale study.

\section{References}

1. Acute Upper Gastrointestinal Bleeding: Management. National Institute for Health and Clinical Excellence: Guidance. London, 2012.

2. Feinman M, Haut ER. Upper gastrointestinal bleeding. Surg Clin North Am. 2014; 94:43-53.

3. Villanueva C, Piqueras M, Aracil C, Gomez C, LopezBalaguer JM, Gonzalez B, Gallego A, Torras X, Soriano G, Sainz S, Benito S, Balanzo J. A randomized controlled trial comparing ligation and sclerotherapy as emergency endoscopic treatment added to somatostatin in acute variceal bleeding. J Hepatol. 2006; 45:560-567.

4. Peng Y, Qi X, Dai J, Li H, Guo X. Child-Pugh versus MELD score for predicting the in-hospital mortality of acute upper gastrointestinal bleeding in liver cirrhosis. Int J Clin Exp Med. 2015; 8:751-757.

5. Zou D, Qi X, Zhu C, Ning Z, Hou F, Zhao J, Peng Y, Li
J, Deng H, Guo X. Albumin-bilirubin score for predicting the in-hospital mortality of acute upper gastrointestinal bleeding in liver cirrhosis: A retrospective study. Turk J Gastroenterol. 2016; 27:180-186.

6. Infante-Rivard C, Esnaola S, Villeneuve JP. Role of endoscopic variceal sclerotherapy in the long-term management of variceal bleeding: A meta-analysis. Gastroenterology. 1989; 96:1087-1092.

7. Paquet KJ, Feussner H. Endoscopic sclerosis and esophageal balloon tamponade in acute hemorrhage from esophagogastric varices: A prospective controlled randomized trial. Hepatology. 1985; 5:580-583.

8. Westaby D, Hayes PC, Gimson AE, Polson RJ, Williams R. Controlled clinical trial of injection sclerotherapy for active variceal bleeding. Hepatology. 1989; 9:274-277.

9. Schuman BM, Beckman JW, Tedesco FJ, Griffin JW, Jr., Assad RT. Complications of endoscopic injection sclerotherapy: A review. Am J Gastroenterol. 1987; 82:823-830.

10. Laine L, el-Newihi HM, Migikovsky B, Sloane R, Garcia F. Endoscopic ligation compared with sclerotherapy for the treatment of bleeding esophageal varices. Ann Intern Med. 1993; 119:1-7.

11. Lo GH, Lai KH, Cheng JS, Hwu JH, Chang CF, Chen SM, Chiang HT. A prospective, randomized trial of sclerotherapy versus ligation in the management of bleeding esophageal varices. Hepatology. 1995; 22:466471.

12. Baroncini D, Milandri GL, Borioni D, Piemontese A, Cennamo V, Billi P, Dal Monte PP, D'Imperio N. A prospective randomized trial of sclerotherapy versus ligation in the elective treatment of bleeding esophageal varices. Endoscopy. 1997; 29:235-240.

13. de la Pena J, Rivero M, Sanchez E, Fabrega E, Crespo J, Pons-Romero F. Variceal ligation compared with endoscopic sclerotherapy for variceal hemorrhage: Prospective randomized trial. Gastrointestinal endoscopy. 1999; 49:417-423.

14. Zargar SA, Javid G, Khan BA, Yattoo GN, Shah AH, Gulzar GM, Singh J, Rehman BU, Din Z. Endoscopic ligation compared with sclerotherapy for bleeding esophageal varices in children with extrahepatic portal venous obstruction. Hepatology. 2002; 36:666-672.

15. Schmitz RJ, Sharma P, Badr AS, Qamar MT, Weston 
AP. Incidence and management of esophageal stricture formation, ulcer bleeding, perforation, and massive hematoma formation from sclerotherapy versus band ligation. Am J Gastroenterol. 2001; 96:437-441.

16. Lo GH, Lai KH, Cheng JS, Lin CK, Huang JS, Hsu PI, Chiang HT. Emergency banding ligation versus sclerotherapy for the control of active bleeding from esophageal varices. Hepatology. 1997; 25:1101-1104.

17. Al Traif I, Fachartz FS, Al Jumah A, Al Johani M, alOmair A, al-Bakr F, al-Knawy B, el-Hafi A, Khan MH. Randomized trial of ligation versus combined ligation and sclerotherapy for bleeding esophageal varices. Gastrointest Endosc. 1999; 50:1-6.

18. Masci E, Stigliano R, Mariani A, Bertoni G, Baroncini D, Cennamo V, Micheletti G, Casetti T, Tansini P, Buscarini E, Ranzato R, Norberto L. Prospective multicenter randomized trial comparing banding ligation with sclerotherapy of esophageal varices. Hepatogastroenterology. 1999; 46:1769-1773.

19. Awad AE, Soliman HH, Saif SA, Darwish AM, Mosaad S, Elfert AA. A prospective randomised comparative study of endoscopic band ligation versus injection sclerotherapy of bleeding internal haemorrhoids in patients with liver cirrhosis. Arab J Gastroenterol. 2012; 13:77-81.

20. de Franchis R, Baveno VIF. Expanding consensus in portal hypertension: Report of the Baveno VI Consensus Workshop: Stratifying risk and individualizing care for portal hypertension. J Hepatol. 2015; 63:743-752.

21. Tripathi D, Stanley AJ, Hayes PC, Patch D, Millson C,
Mehrzad H, Austin A, Ferguson JW, Olliff SP, Hudson M, Christie JM, Clinical S, Standards Committee of the British Society of G. U.K. guidelines on the management of variceal haemorrhage in cirrhotic patients. Gut. 2015; 64:1680-1704.

22. Avgerinos A, Armonis A, Stefanidis G, Mathou N, Vlachogiannakos J, Kougioumtzian A, Triantos C, Papaxoinis C, Manolakopoulos S, Panani A, Raptis SA. Sustained rise of portal pressure after sclerotherapy, but not band ligation, in acute variceal bleeding in cirrhosis. Hepatology. 2004; 39:1623-1630.

23. Dai C, Liu WX, Jiang M, Sun MJ. Endoscopic variceal ligation compared with endoscopic injection sclerotherapy for treatment of esophageal variceal hemorrhage: A metaanalysis. World J Gastroenterol. 2015; 21:2534-2541.

24. Hwang JH, Shergill AK, Acosta RD, et al. The role of endoscopy in the management of variceal hemorrhage. Gastrointest Endosc. 2014; 80:221-227.

25. Truesdale RA, Jr., Wong RK. Complications of esophageal variceal sclerotherapy. Gastroenterol Clin North Am. 1991; 20:859-870.

26. Zhu J, Qi X, Yu H, Su C, Guo X. Acid suppression in patients treated with endoscopic therapy for the management of gastroesophageal varices: A systematic review and meta-analysis. Expert Rev Gastroenterol Hepatol. 2018; 12:617-624.

(Received September 30, 2018; Revised October 27, 2018; Accepted October 27, 2018) 